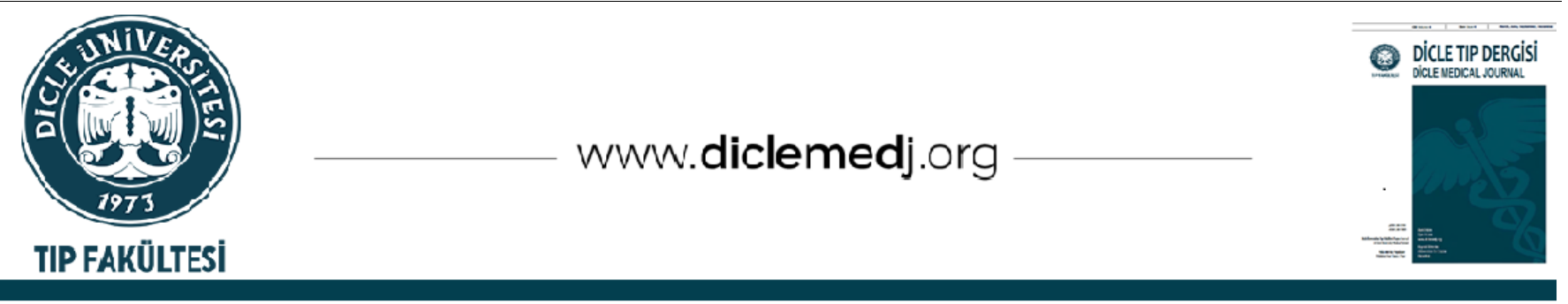

Özgün Araştırma / Original Article

\title{
Malign Plevral Mezotelyoma Tanısında 18F-FDG PET/BT Görüntülemenin Rolü
}

\author{
İhsan Kaplan ${ }^{D_{1}}$, Ayten Gezici ${ }^{D_{2}}$ \\ 1 Sağlık Bilimleri Üniversitesi, Gazi Yaşargil Eğitim ve Araştırma Hastanesi, Nükleer Tıp Kliniği, Diyarbakır, Türkiye \\ 2 Dicle Üniversitesi Tıp Fakültesi, Nükleer Tıp Anabilim Dalı, Diyarbakır, Türkiye
}

Geliş: 01.04.2021; Revizyon: 17.05.2021; Kabul Tarihi: 18.05.2021

$\ddot{0} \mathbf{z}$

Amaç: Malign plevral mezotelyoma (MPM) ön tanısı ile 18F-FDG PET/BT görüntülemesi yapılan hastalarda, plevral kalınlık ve mediastinal lenf nodlarının, boyut ile SUVmax değerlerinin tanısal etkinliğini araştırmayı amaçladık.

Yöntemler: Mayıs 2018 ile Şubat 2020 tarihleri arasında kliniğimize, MPM ön tanısıyla başvuran ve 18F-FDG PET/BT görüntülemesi yapılan 54 hasta retrospektif olarak incelendi. Hastaların 28'i kadın $(\% 51,8)$ ve 26'sı erkek $(\% 48,2)$ olup ortalama yaşları 58,8 idi. Tüm hastaların plevral kalınlık değerleri, mediastinal lenf nodlarının boyutları ve tüm lezyonların SUVmax değerleri ölçüldü. PET/BT görüntüleme sonrası yapılan histopatolojik inceleme sonucu hastaların 23'ünde MPM, 20'sinde benign plevral hastalık (BPH) ve 11'inde metastatik plevral hastalık (MPH) saptandı.

Bulgular: Tüm gruplar arasında plevral kalınlığın median SUVmax değeri açısından yapılan karşılaștırmada; istatistiki anlamlılık bulundu ( $\mathrm{p}=0.003$ ). Plevral kalınlığın median SUVmax parametresi ikili grup karşılaştırılmalarında; $\mathrm{BPH}$ grubun median SUVmax değeri MPM ve MPH'ya göre istatistiki anlamlı olacak şekilde düşük bulundu ( $p$ değerleri sırasıyla p:0.034 ve p:0.023). Diğer parametrelerde ise MPM ile diğer gruplar karşılaştırıldığında istatistiki anlamlı fark bulunmadı. MPM grubunu tespit etmedeki SUVmax cut-off değeri 6,75 alındığında \%69,6 sensitivite ve \%67,6 spesifiteye sahip olup istatistiki anlamlı fark bulundu.

Sonuç: Malign plevral mezotelyomayı diğer plevral patolojilerden ayırt etmede plevral kalınlığın median SUVmax değerinin kullanılabileceği sonucuna varıldı.

Anahtar kelimeler: Malign plevral mezotelyoma, FDG, PET/BT, SUVmax

DOI: 10.5798/dicletip.944400

Yazışma Adresi / Correspondence: İhsan Kaplan, Sağlık Bilimleri Üniversitesi, Gazi Yaşargil Eğitim ve Araştırma Hastanesi, Nükleer Tıp Kliniği, 21070, Kayapınar, Diyarbakır, Türkiye e-mail: drihsankaplan@hotmail.com 


\title{
The Role of 18F-FDG PET/CT in the Diagnosis of Malignant Pleural Mesothelioma
}

\begin{abstract}
Objective: We aimed to investigate the diagnostic efficiency of pleural thickness and mediastinal lymph nodes, size and SUVmax values in patients with a pre-diagnosis of malignant pleural mesothelioma (MPM) who underwent 18F-FDG PET/CT imaging.

Methods: Fifty-four patients who were admitted to our clinic with a diagnosis of MPM and had 18F-FDG PET/CT imaging between May 2018 and February 2020 were retrospectively analyzed. 28 of the patients were female $(\% 51,8)$ and 26 were male $(\% 48,2)$ and their average age was 58,8 . Pleural thickness values of all patients, sizes of mediastinal lymph nodes and SUVmax values of all lesions were measured. Histopathological examination after PET/CT imaging revealed MPM in 23 patients, benign pleural disease (BPH) in 20, and metastatic pleural disease (MPH) in 11 patients.
\end{abstract}

Results: In the comparison between all groups in terms of median SUVmax value of pleural thickness; statistical significance was found ( $\mathrm{p}=0.003$ ). Median SUVmax parameter of pleural thickness in paired group comparisons; The median SUVmax value of the BPH group was found to be statistically significantly lower than MPM and MPH ( $p$ values p:0.034 and p:0.023 respectively). In other parameters, when MPM and other groups were compared, no statistically significant difference was found. When the cut-off value of SUVmax for detecting MPM group was taken as 6,75, it had $\% 69,6$ sensitivity and \%67,6 specificity, and a statistically significant difference was found.

Conclusion: It was concluded that the median SUVmax value of pleural thickness can be used to distinguish malignant pleural mesothelioma from other pleural pathologies.

Keywords: Malignant pleural mesothelioma, FDG, PET/CT, SUVmax.

\section{GíRiş}

Malign mezotelyoma, plevra, periton, tunika vaginalis ve perikardiyumu etkileyebilen serozal yüzeylerden kaynaklanan nadir bir malign tümördür. En yaygın tip, tüm malign mezotelyomaların yaklaşık \%65'ini oluşturan malign plevral mezotelyomadır (MPM) ${ }^{1,2}$. Histolojik olarak epiteloid, sarkomatoid ve bifazik olmak üzere üç tipi vardır. En sık görülen histolojik subtip epiteloid MPM'dir ${ }^{3}$. Genel medyan sağkalım 9,5 aydır, 1 yıllık sağkalım $\% 41,4$ ve 3 yıllık sağkalım \%12,0'dir. Sağkalım, performans durumuna ve histolojik alt tipe göre değişiklik göstermektedir. Hastalığın mesleki doğası nedeniyle erkek (4:1) egemenliği vardır4. Plevranın en sık primer malignitesi mezotelyoma, en sik sekonder malignitesi ise akciğer adenokarsinomunun metastazıdır ${ }^{5,6}$. Tanı anında Bilgisayarlı Tomografi (BT) ile plevral effüzyon, plevral kalınlaşma ve interlobar fissür tutulumu ve göğüs duvarı invazyonu gösterilir. BT için tanıda plevral malignite için sırasıyla $\% 68$ ve $\% 78$ 'lik bir duyarlılık ve özgüllük bildirilmiştir. MPM'de çevresel plevral kalınlaşma ve mediastinal plevral tutulum daha sık görülmesine rağmen BT, MPM'yi metastatik plevral maligniteden ayırt edemez ${ }^{7}$. Manyetik Rezonans Görüntüleme (MRG) MPM'de göğüs duvarı invazyonu, diyafram tutulumu ve vasküler invazyonu saptamada BT'den daha yüksek duyarlılığa sahiptir.

Radyolojik yöntemler MPM'nın morfolojik değişiklikleri hakkında bilgi vermesine rağmen birçok olguda bu bilgiler yeterli değildir. $\mathrm{Bu}$ nedenle morfolojik değişiklerin yanı sıra hastalığın metabolik durumu hakkında bilgi veren 18F-Florodeoksiglukoz (18F-FDG) Pozitron Emisyon Tomografi (PET)/BT yöntemiyle MPM tanı ve ayırıcı tanısında kullanılmaktadır 9 .

Bu çalışmadaki amacımız MPM ön tanısı ile 18FFDG PET/BT görüntülemesi yapılan hastalarda plevranın kalınlığın ve mediastinal lenf nodlarının boyutu, plevral kalınlığın SUVmax değeri ile mediastinal lenf nodlarının SUVmax 
değerlerinin, hastalığın tanısal rolünü değerlendirmektir.

\section{YÖNTEMLER}

$\mathrm{Bu}$ çalışma yürürlükteki mevcut yasalar ve iyi klinik uygulamalar kılavuzu eşliğinde Dicle Üniversitesi Tıp Fakültesi etik komiteden onay alınarak gerçekleştirildi (Onay no:2020/99). Kliniğimize Mayıs 2018 ile Şubat 2020 tarihleri arasında toraks BT ile plevral kalınlaşması olduğu belirlenmiş, MPM ön tanısıyla başvuran, 18F-FDG PET/BT görüntülemesi yapılan ve sonrasında histopatolojik tanısı konmuş 54 hasta retrospektif olarak incelendi. Sadece Plevral effüzyon sonucu ile MPM tanısı alan hastalar çalışmamızdan dışlanmıştır. Plevral kalınlık ile mediastinal lenf nodu SUVmax değerleri ise ölçülemeyen hastalar 0 (sıfır) olarak alındı.

$\mathrm{Bu}$ hastalar MPM, Benign plevral hastalık (BPH) ve Metastatik plevral hastalık şeklinde üç gruba ayrıldı. Bu gruplarda ayrı ayrı plevranın kalınlığı, mediastinal lenf nodlarının boyutu, plevral kalınlığın SUVmax değeri ile mediastinal lenf nodlarının SUVmax değerleri ölçülüp kaydedildi.

\section{Yöntem ve Cihaz Bilgisi}

Tüm vücut PET/BT taraması 3D-TOF Siemens Biograph Horizon marka (Siemens Healthcare, Erlangen, Germany) cihaz kullanılarak gerçekleştirildi. 18F-FDG PET/BT görüntüleme minimum 6 saat açlık sonrası kan şekeri $\leq 140$ $\mathrm{mg} / \mathrm{dl}$ olan hastalara çekildi. Hastalara 0,1 $\mathrm{mCI} / \mathrm{kg}$ dozda 18F-FDG intravenöz olarak enjekte edildikten 60 dakika sonra, atenüasyon düzeltmesi için düşük dozlu 16 kesitli BT (80 mA ve $120 \mathrm{kV}$ ) ile verteks ve üst uyluk bölgesini içerek şekilde kraniokaudal yönde $3 \mathrm{~mm}$ kesit kalınlığı görüntüleme yapıldı. Daha sonra aynı aralıkta kraniokaudal doğrultuda yatak pozisyonu başına 3 dakika olacak şekilde PET taraması yapıldı.

\section{Görüntü Değerlendirilmesi}

En az 10 yıllık deneyime sahip iki nükleer tıp uzmanı tarafından syngo via (Siemens Healthcare, Erlangen, Germany) iş istasyonunda PET, BT ve füzyon görüntüleri değerlendirildi. Plevral kalınlaşmalardan ve mediastinal lenf nodlarından metabolik olarak en yoğun bölgeden Volume-Of-Interest çizilerek SUVmax değerleri hesaplandı. Her hasta için en yüksek SUVmax değerleri hesaplandı. BT görüntülerinden plevranın en kalın olduğu yerden ve mediastende en büyük lenf nodundan boyut ölçümleri yapıldı.

\section{İstatistiksel Analiz}

Verilerin istatistiki değerlendirilmesinde IBM SPSS Statistics 25.0 programı kullanıldı. Üç ve daha fazla grubun arasında nicel bir değişken açısından farklılık olup olmadığının test edilmesi için nonparametrik Kruskal-Wallis $\mathrm{H}$ testi ve parametrik bir test olan one-way ANOVA kullanıldı. İkili gruplar arasındaki farklılığı araştırmak için post-hoc testler kullanıldı. MPM hastalarını ayırt etmek için plevral kalınlığın SUVmax cut-off değeri ROC eğrisi analizi ile yapıldı. Bu testlerde p değeri $\leq 0,05$ olan değerler istatistiksel anlamlı farklılık olduğu kabul edildi. Sonuçlar sürekli değişkenler için değişken normal dağılım gösteriyorsa ortalama \pm standart sapma (SS) değerleri, normal dağılım göstermiyor ise ortanca (minimum-maximum) değerleri verilerek gösterildi.

\section{BULGULAR}

Hastaların 28'i kadın $(\% 51,8)$ ve 26'sı erkek (\%48,2), ortalama yaşları 58,8 (yaş aralığı 27-87) idi. 23 MPM hastasının 18'i (\%78) epiteloid alt tip (Resim 1) ve 5'i (\%22) bifazik alt tip (Resim 2) idi. MPM hastalarının 15'i (\%65) kadın ve 8'i (\%35) erkek olup yaş ortalamaları 60,6 idi. BPH grubundaki 20 hastanın 11'inin histopatolojisi normal plevral kalınlaşma ve 9'unun histopatolojisi plevrit (1'i granülomatöz plevrit, 1'i subakut-kronik plevrit, 3'ü kronik plevrit, 4'ü subakut plevrit) şeklinde raporlandı. 11 MPH hastasının 10'u (\%90) akciğer kanserinin ve 1'i (\%10) prostat kanserinin 
plevral metastazlarından oluşmakta olup hasta datası Tablo 1 ve Tablo 2'de detaylandırılmıştır.
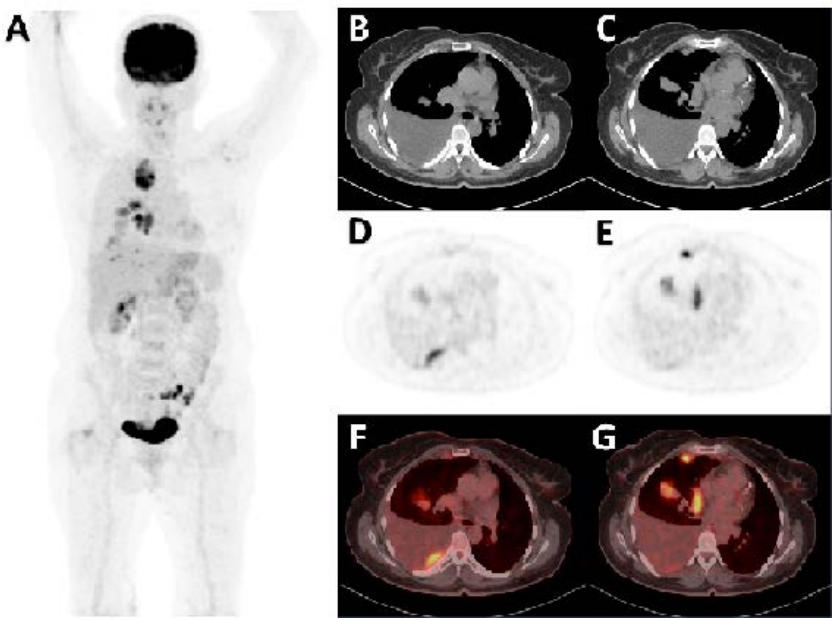

Resim 1: 52 yaşında, kadın hastada MPM'nın epiteloid alt tipi. Plevral kalınlığın en geniş yerindeki ölçümü $55 \mathrm{~mm}$ ve SUVmax:12,4 ile mediastinal lenf nodu uzun çapın ölçümü $9 \mathrm{~mm}$ ve SUVmax:2,1 olarak bulduk. Sağ akciğerde anterior, kostal ve mediastinal plevral tutulumu, major fissür tutulumu ve plevral effüzyondaki kalınlașma alanı gösterilmiștir. A. Maksimum İntensite Projeksiyonu (MIP) görüntüsü. B-C Toraks aksiyal BT görüntüleri. D-E. Toraks aksiyal PET görüntüleri. F-G. Toraks aksiyal PET/BT füzyon görüntüleri.
A

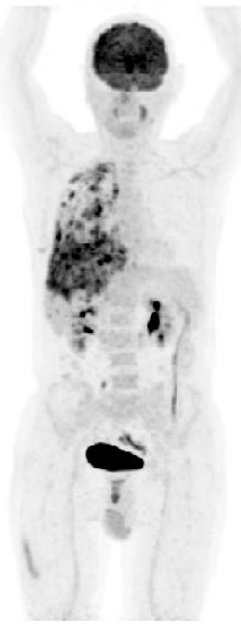

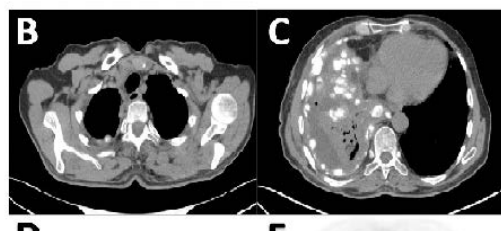

D

E

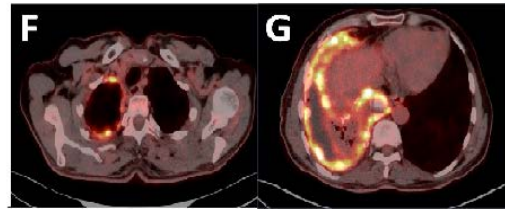

Resim 2: 70 yaşında, erkek hastada MPM'nın bifazik alt tipi ve sağ akciğerde yaygın plevral tutulumları izlenmektedir. Plevral kalınlığın en geniş yerindeki ölçümü 12,7 mm ve SUVmax:13,6 ile mediastinal lenf nodunun uzun çapının ölçümü $8 \mathrm{~mm}$ ve SUVmax:4,2 olarak ölçüldü. A. Maksimum İntensite Projeksiyonu (MIP) görüntüsü. B-C Toraks aksiyal BT görüntüleri. D-E. Toraks aksiyal PET görüntüleri. F-G. Toraks aksiyal PET/BT füzyon görüntüleri.

Tablo I: Tüm Hastaların Verileri

\begin{tabular}{|c|c|c|c|c|c|c|c|}
\hline Hasta & Cinsiyet & Yaş & Histopatoloji & Plevral kalınlık mm & Plevral kalınlık SUVmax & Mediastinal lenf nodu $\mathrm{mm}$ & Mediastinal lenf nodu SUVmax \\
\hline 1. & $\mathrm{E}$ & 70 & $\mathrm{~B}$ & 12 & 13,6 & 8 & 4,2 \\
\hline 2. & $\mathrm{E}$ & 50 & E & 11 & 16,3 & 5 & 4,2 \\
\hline 3. & K & 42 & $\mathrm{E}$ & 29 & 13,3 & 12 & 6,1 \\
\hline 4. & $\mathrm{E}$ & 74 & B & 23 & 11,5 & 18 & 19,3 \\
\hline 5. & $\mathrm{E}$ & 78 & B & 7 & 9,9 & 18 & 5,5 \\
\hline 6. & K & 79 & $\mathrm{E}$ & 5 & 3,4 & 8 & 3,5 \\
\hline 7. & K & 57 & $\mathrm{E}$ & 21 & 6,9 & 0 & 0 \\
\hline 8. & K & 57 & $\mathrm{E}$ & 8 & 3,5 & 9 & 2,1 \\
\hline 9. & K & 53 & $\mathrm{E}$ & 55 & 10,7 & 16 & 12 \\
\hline 10 & $\mathrm{E}$ & 56 & $\mathrm{E}$ & 20 & 11 & 0 & 0 \\
\hline 11. & K & 56 & E & 38 & 2,8 & 0 & 0 \\
\hline 12 & K & 74 & $\mathrm{E}$ & 7 & 9,9 & 18 & 5,5 \\
\hline 13. & K & 66 & $\mathrm{E}$ & 17 & 12,3 & 12 & 3,3 \\
\hline 14 & K & 59 & E & 14 & 11 & 10 & 3,8 \\
\hline 15 & K & 59 & $\mathrm{E}$ & 8 & 3,3 & 6 & 3,1 \\
\hline 16 & $\mathrm{E}$ & 52 & $\mathrm{E}$ & 11 & 12,3 & 12 & 5,1 \\
\hline 17. & K & 37 & B & 18 & 15,4 & 18 & 3 \\
\hline 18. & K & 74 & $\mathrm{E}$ & 50 & 24,3 & 10 & 3,9 \\
\hline 19. & $\mathrm{E}$ & 59 & $\mathrm{E}$ & 15 & 8,5 & 9 & 3,7 \\
\hline
\end{tabular}




\begin{tabular}{|c|c|c|c|c|c|c|c|}
\hline 20 & $\mathrm{E}$ & 66 & $\mathrm{E}$ & 23 & 10,8 & 10 & 5 \\
\hline 21. & K & 52 & $\mathrm{E}$ & 6 & 3,2 & 0 & 0 \\
\hline 22. & K & 67 & B & 5 & 2,3 & 8 & 2,4 \\
\hline 23. & K & 57 & $\mathrm{E}$ & 0 & 3,5 & 0 & 0 \\
\hline 24. & $E$ & 87 & $\mathrm{~N}$ & 0 & 0,5 & 20 & 4,9 \\
\hline 25. & $E$ & 79 & $\mathrm{~N}$ & 17 & 3,5 & 0 & 0 \\
\hline 26 & K & 56 & $\mathrm{~N}$ & 8 & 0,5 & 5 & 4,1 \\
\hline 27. & $E$ & 49 & $\mathrm{~N}$ & 11 & 4,1 & 0 & 0 \\
\hline 28. & $\mathrm{E}$ & 71 & $\mathrm{~N}$ & 12 & 6,6 & 14 & 8,1 \\
\hline 29. & K & 79 & $\mathrm{~N}$ & 7 & 3,5 & 0 & 0 \\
\hline 30. & K & 49 & $\mathrm{~N}$ & 7 & 4,1 & 6 & 4,6 \\
\hline 31. & $\mathrm{E}$ & 61 & $\mathrm{~N}$ & 13 & 2,7 & 0 & 0 \\
\hline 32. & K & 50 & $\mathrm{~N}$ & 5 & 2,9 & 0 & 0 \\
\hline 33. & K & 68 & $\mathrm{~N}$ & 5 & 2 & 14 & 4,4 \\
\hline 34 & $E$ & 78 & $\mathrm{~N}$ & 0 & 1,8 & 15 & 8,6 \\
\hline 35 & $\mathrm{E}$ & 41 & $S p$ & 8 & 2,9 & 15 & 3,5 \\
\hline 36. & K & 55 & $\mathrm{Kp}$ & 12 & 4,8 & 0 & 0 \\
\hline 37. & $E$ & 29 & SKp & 13 & 6,4 & 11 & 4,6 \\
\hline 38. & $\mathrm{E}$ & 69 & $S p$ & 10 & 4,9 & 0 & 0 \\
\hline 39. & K & 41 & $S p$ & 14 & 3,3 & 0 & 0 \\
\hline 40 & K & 67 & $S p$ & 7 & 4,3 & 8 & 4 \\
\hline 41 & K & 44 & Kp & 5 & 3,9 & 0 & 0 \\
\hline 42 & $\mathrm{E}$ & 27 & Gp & 14 & 19,4 & 19 & 10,6 \\
\hline 43. & $E$ & 48 & $\mathrm{Kp}$ & 49 & 11,3 & 16 & 4,1 \\
\hline 44 & $\mathrm{E}$ & 61 & $A c$ & 5 & 5,2 & 16 & 4,4 \\
\hline 45 & K & 38 & $A c$ & 14 & 4,9 & 0 & 0 \\
\hline 46 & $\mathrm{E}$ & 61 & $A c$ & 18 & 8,4 & 10 & 3,4 \\
\hline 47. & $\mathrm{E}$ & 60 & Pc & 9 & 11,7 & 11 & 5,1 \\
\hline 48 & K & 61 & $A c$ & 13 & 11,8 & 13 & 6 \\
\hline 49. & K & 40 & $A c$ & 12 & 10,9 & 12 & 5,7 \\
\hline 50 & K & 55 & $A C$ & 6 & 8,6 & 8 & 6 \\
\hline 51. & $E$ & 64 & $A C$ & 10 & 2,8 & 15 & 9,8 \\
\hline 52. & E & 56 & $A c$ & 17 & 11,6 & 13 & 11,9 \\
\hline 53. & $E$ & 82 & $A c$ & 16 & 6,9 & 14 & 6 \\
\hline 54. & $\mathrm{E}$ & 57 & $A c$ & 28 & 38,4 & 6 & 5,8 \\
\hline
\end{tabular}

E: Erkek, K: Kadın, B: Bifazik alt tip, E:Epiteloid alt tip, N:Normal plevral kalınlaşma, Ac: Akciğer kanseri, Pc: Prostat ca, Gp: Granülomatöz plevrit, Kp: Kronik plevrit, Sp: Subakut plevrit, SKp: Subakut-Kronik plevrit, mm: milimetre 
Tablo II: Tanımlayıcı veriler

\begin{tabular}{|c|c|c|c|c|}
\hline & MPM & BPH & MPH & Total \\
\hline \multicolumn{5}{|l|}{ Cinsiyet } \\
\hline Erkek & $8(34,8)$ & $11(55)$ & $7(63,6)$ & 26 \\
\hline Kadın & $15(65,2)$ & $9(45)$ & $4(36,4)$ & 28 \\
\hline \multicolumn{5}{|l|}{ Yaş } \\
\hline & 60,6 (37-79) & $57,4(27-87)$ & $57,7(38-82)$ & 58,8 \\
\hline & 23 & 20 & 11 & \\
\hline Sayı & & & & 54 \\
\hline & 42,6 & 37 & 20,4 & \\
\hline Sayı (\%) & & & & 100 \\
\hline Histopatoloji & $\begin{array}{l}18 \text { Epiteloid } \\
5 \text { Bifazik }\end{array}$ & $\begin{array}{l}11 \text { Normal } \\
9 \text { Plevrit }\end{array}$ & $\begin{array}{l}10 \text { Akciğer ca } \\
1 \text { Prostat ca }\end{array}$ & \\
\hline
\end{tabular}

MPM, BPH ve MPH plevra kalınlığının SUVmax değerleri sirasiyla 10,7 (2,3-24,3), 3,7 (0,5-19,4) ve $8,6(2,8-38,4)$ olarak bulundu. Tüm gruplar arasında yapılan karşılaştırmada; plevra kalınlığının median SUVmax değeri istatistiki anlamlı olacak șekilde farklı bulundu ( $\mathrm{p}=0,003)$. Post-hoc testleri ile ikili grup karşılaştırmaları yapıldığında BPH grubunda plevral kalınlığın median SUVmax değeri MPM ve MPH median SUVmax değerinden istatistiki anlamlı olacak şekilde daha düşük bulundu (sırasıyla $\mathrm{p}=0,034$ ve $p=0,023)$. MPM ve MPH arasinda plevral kalınlığın median SUVmax değeri açısından istatistiki anlamlı farklılık izlenmedi $(p>0,05)$ (Tablo3).

MPM, BPH ve MPH mediastinal lenf nodunun SUVmax değerleri sırasıyla $3,7(0,0-19,3), 3,8$ $(0,0-10,6)$ ve $5,8(0,0-11,9)$ olarak bulundu. Tüm gruplar arasında mediastinal lenf nodu median SUVmax değeri açısından yapılan karşılaştırmada; istatistiki anlamlı farklılık izlendi $(p=0,029)$. MPH'li hastaların median SUVmax değerleri BPH ve MPM grubuna göre istatistiki anlamlı olacak şekilde daha yüksek bulundu (sirasiyla p:0,023 ve p:0,016). MPH ile MPM arasinda mediastinal lenf nodu SUVmax değeri açısından istatistiki anlamlı farklılık bulunmadı $(p>0,05)$ (Tablo3).

Tablo III: İstatistiki Veriler

\begin{tabular}{|c|c|c|c|c|c|}
\hline & $\begin{array}{c}\text { MPM } \\
\text { Grup } 1 \\
\text { Median } \\
\text { (Min-Max) }\end{array}$ & $\begin{array}{c}\text { BPH } \\
\text { Grup 2 } \\
\text { Median } \\
\text { (Min-Max) }\end{array}$ & $\begin{array}{c}\text { MPH } \\
\text { Grup } 3 \\
\text { Median } \\
\text { (Min-Max) }\end{array}$ & $\mathbf{P}$ & Post-hoc \\
\hline $\begin{array}{l}\text { Plevral kalınlık } \\
\text { mm boyutu }\end{array}$ & $\begin{array}{c}14,0 \\
(0,0-55,0)\end{array}$ & $\begin{array}{c}9,2 \\
(0,0-49,0)\end{array}$ & $\begin{array}{c}13,0 \\
(5,0-28,0)\end{array}$ & 0,115 & Anlamlı bir fark yok \\
\hline Plevral kalınlık SUVmax & $\begin{array}{c}10,7 \\
(2,3-24,3)\end{array}$ & $\begin{array}{c}3,7 \\
(0,5-19,4)\end{array}$ & $\begin{array}{c}8,6 \\
(2,8-38,4)\end{array}$ & 0,003 & $\begin{array}{l}\text { Grup 1-2; } p=0,034 \\
\text { Grup 2-3; } p=0,023\end{array}$ \\
\hline $\begin{array}{l}\text { Mediastinal lenf nodu } \mathrm{mm} \\
\text { boyutu }\end{array}$ & $\begin{array}{c}9,0 \\
(0,0-18,0)\end{array}$ & $\begin{array}{c}6,3 \\
(0,0-20,0)\end{array}$ & $\begin{array}{c}12,0 \\
(0,0-16,0)\end{array}$ & 0,380 & Anlamlı bir fark yok \\
\hline $\begin{array}{l}\text { Mediastinal lenf nodu } \\
\text { SUVmax }\end{array}$ & $\begin{array}{c}3,7 \\
(0,0-19,3)\end{array}$ & $\begin{array}{c}3,8 \\
(0,0-10,6)\end{array}$ & $\begin{array}{c}5,8 \\
(0,0-11,9)\end{array}$ & 0,029 & $\begin{array}{l}\text { Grup 2-3; }=0,023 \\
\text { Grup 2-3; } p=0,016\end{array}$ \\
\hline
\end{tabular}

MPM: Malign Plevral Mezotelyoma, BPH: Benign Plevral Hastalık, MPH: Metastatik Plevral Hastalık

ROC eğri analizi ile SUVmax cut-off değeri 6,75 alındığında MPM'yi tespit etmede \%69,6 sensitivite ve $\% 67,6$ spesifiteye sahip olup istatistiksel olarak anlamlıdır (Eğri Altındaki Alan (AUC): 0,67 $\pm 0,077, \% 95$ güven aralığı: 0,516-0,817,) (Resim 3).
ROC eğri analizi ile SUVmax cut-off değeri 4,85 alındığında Malign (MPM ile MPH) ile BPH plevral patolojileri ayırt etme \%76,5 sensitivite ve $\% 75$ spesifiteye sahip olup istatistiksel olarak anlamlıdır (AUC):0,78 $\pm 0,067, \% 95$ güven aralığı: 0,652-0,913) ) (Resim 3). 


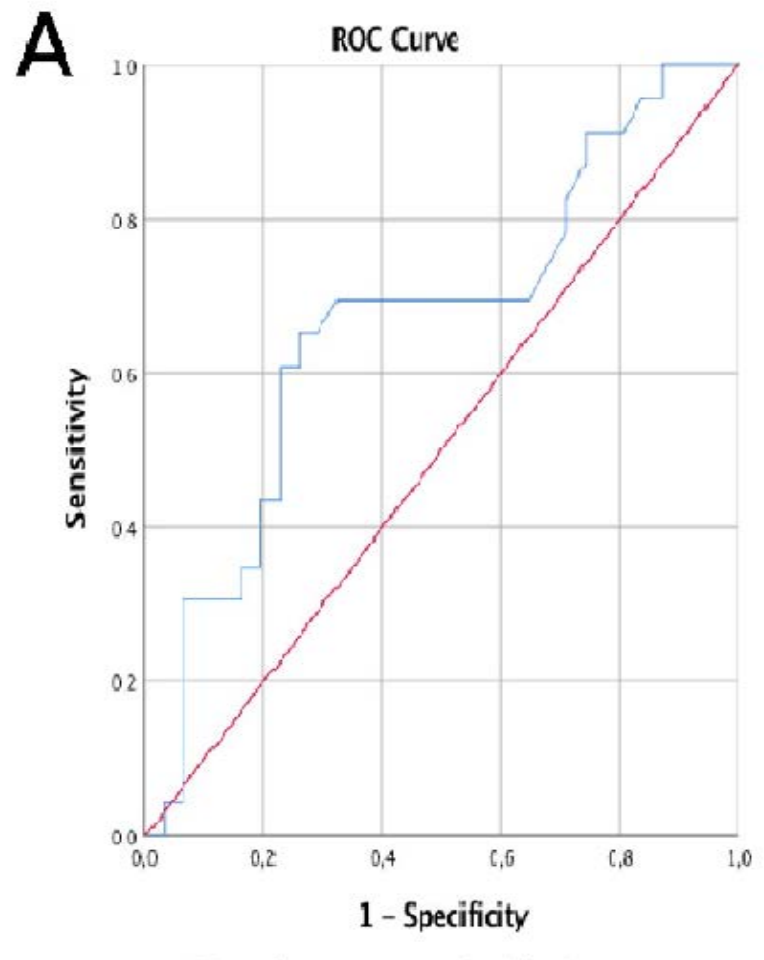

Diagonal seçments are produced by ties.

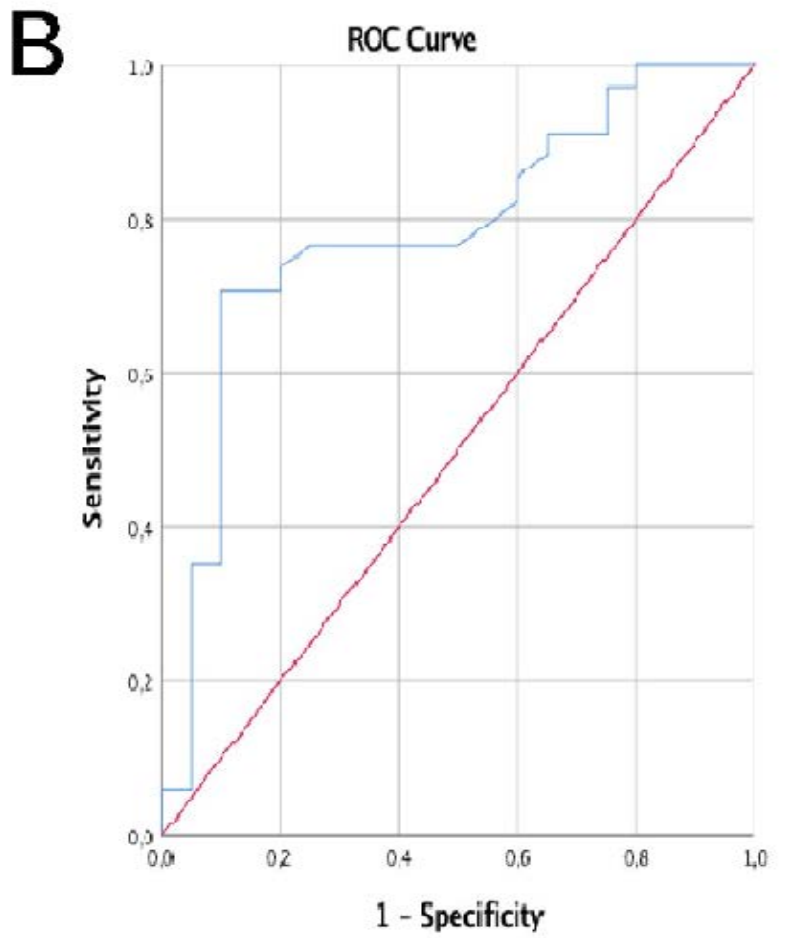

Diagonal segments àe poduced by ties.

Resim 3: A. MPM tespit etme ROC eğri analizi. B. Malign ile Benign plevral patolojileri ayırt etme ROC eğri analizi.

\section{TARTIŞMA}

Malign plevral mezoteliyomada 18F-FDG PET/BT'nin tanıdaki rolünü araştırmak amacıyla plevral kalınlaşması olan hastaların değerlendirildiği bu retrospektif çalışmamızda plevral kalınlığın SUVmax cut-off değeri 6,75 alındığında MPM'yi tespit etmede yüksek sensitivite ve spesifiteye sahip olduğunu saptadık.

Ülkemizde yapılan 333'ü $(\% 55,5)$ erkek, 267'si (\%44,5) kadın toplam 600 MPM hastasının değerlendirildiği bir çalışmada hastaların yaş ortalaması $\quad 61,1 \pm 11,7 \quad$ (26-90) yl bulunmuştur ${ }^{10}$. Başka bir çalışmada 37 hastanın 18'i erkekti ve hastaların yaş ortalaması $59,0 \pm 11,2$ yıldı11. Çalışmamızda hastaların ortalama yaşı literatürle benzer olmasına rağmen kadın hasta oranımız daha yüksek izlendi. MPM ile diğer plevral patolojilerin cinsiyet açısından yapılan karşılaştırmada; MPM hastalarında kadın, diğer plevral patolojilerde ise erkek cinsiyetin baskın olduğu görüldü.

Yapılan bir çalışmada, 31 hastanın 17'si malign (MPM), 14'ü benign plevral hastalıktan (9 asbest plörezisi ve 5 diffüz plevral fibrozis) oluşan iki grupta ortalama SUVmax değerleri MPM olgularında $6,5 \pm 3,4$ ve benign plevral hastalıklar için $0,8 \pm 0,6$ bulunmuş. İki plevral hastalık grubu karşılaştırıldığında, SUVmax için 2,2'lik cut-off değerinde sensitivite \%94,1 ve spesifite \%100 olarak bulunmuş ${ }^{12}$. Yapılan bir diğer çalışmada 37'si MPM ve 13'ü benign plevral patolojisi olan hastalarda, MPM için SUVmax cut-off 2,5 alındığında sensitivite \%91,8 ve spesifite \%61,5 olarak bulunmuş ${ }^{13}$. Akdeniz ve ark yaptığı çalışmada MPM'li 29 hastada tümör medyan SUVmax değeri 7.7 bulunmuştur ${ }^{14}$. Çalışmamızda en yüksek SUVmax değerleri MPM grubunda bulunurken, MPH grubunda da BPH grubundan yüksek bulunmuştur. Bulgularımız MPM'yı BPH ayırt etmede 18F-FDG PET/BT görüntülemenin 
faydalı olacağını göstermektedir. MPM grubunu tespit etmedeki SUVmax cut-off değeri 6,75 alındığında \%69,6 sensitivite ve $\% 67,6$ spesifiteye, Malign ile Benign plevral patolojileri ayırt etmedeki SUVmax cut-off değeri 4,85 alındığında \%76,5 sensitivite ve \%75 spesifiteye değerlerini elde ettik. MPM'yı ayırt etmek için bulduğumuz cut-off değerinin, sensitivite ve spesifitenin farklı olmasinın nedeni hasta gruplarının farklılı̆̆ından kaynaklanıyor olabilir.

Yapılan bir çalışmada, 42'si benign hastalıklardan (sarkoidoz, tüberküloz ve lenfadenit) ve 52'si malign hastalıklarından (lenfoma ve metastatik hastalık) oluşan hasta gruplarında; malign grupta mediastinal lenf nodlarının uzun çapı $6,04 \pm 3,83 \mathrm{~mm}$ olup SUVmax'1 12,59 $\pm 5,50$ olarak bulundu. Benign grupta mediastinal lenf nodlarının uzun çapı $2,86 \pm 1,02 \mathrm{~cm}$ olup SUVmax 13,10 $\pm 5,21$ olarak bulunmuştur 15 . Histopatolojik değerlendirme sonrası 20'si benign (12 tüberküloz ve 8 sarkoidoz) ve $15^{\prime}$ i malign (lenfoma) olarak raporlanan 35 hastanın mediastinal lenf nodlarının SUVmax'ı değerlendirilmiș. Benign mediastinal lenf nodlarının SUVmax'ı 5,02 \pm 3,26 arasinda ve malign mediastinal lenf nodlarının SUVmax'ı ise 10,8 $\pm 8,12$ arasında bulunmuştur. Benign ve malign patoloji arasında istatistiksel olarak anlamlı farklılık bulunmuştur ( $\mathrm{P}<0,0059) 16$. Çalışmamızda mediastinal lenf nodlarının en yüksek SUVmax değerleri sırasıyla MPH grubunda $(5,8(0,0-$ $11,9))$, sonra MPM grubunda $(3,7(0,0-19,3))$, olup en düşük değer BPH grubunda $(3,8(0,0$ 10,6)) bulundu. MPH'li hastaların median SUVmax değerleri BPH ve MPM grubuna göre istatistiki anlamlı olacak şekilde daha yüksek bulundu. MPH ile MPM arasinda mediastinal lenf nodu SUVmax değeri açısından istatistiki anlamlı farklılık bulunmadı.

Plevral kalınlığın sağkalım analizi ile ilgili yapılan çalışmada; plevral kalınlığın 5,1 mm'yi geçmediğinde 24,2 aylık ve aştığında ise 17,7 ay medyan sağkalım olduğu bildirilmiştir ${ }^{17}$. Ülkemizde yapılan bir çalışmada 215 hastanın BT bulgularını gözden geçirilmiş; 99'u MPM, 39'u MPH ve 77'si BPH olarak değerlendirilmiş olup BT'de $1 \mathrm{~cm}$ 'den fazla plevral kalınlık MPM'yi MPD'den 59/82 duyarlılık/özgüllük değerleri ile ayırt etmektedir. Ayrıca BT'de 1 cm'den fazla plevral kalınlık sırasıyla 47/64 duyarllık/özgüllük değerleri ile malign plevral hastalıkların (MPM + MPD) BPH'tan ayrımı için bağımsız bulgular olduğu belirtilmiştir ${ }^{18}$.

Çalışmamızda en büyük median plevral kalınlaşma MPM ile MPH gruplarında ve 1 cm'den büyük olarak bulundu. BPH'da ise median plevral kalınlaşma $1 \mathrm{~cm}$ 'den küçük bulundu. PET/BT görüntülemesi malign plevral kalınlaşmaların ayırıcı tanısında kullanılamayacağının sonucuna varıldı. Ancak 1 $\mathrm{cm}$ üstü plevral kalınlaşmalar malign hastalık lehine yorumlanabilir.

PET/BT MPM tani, evreleme, tedaviye yanıtta ve aynı zamanda surveyde kullanılmaktadır. MPM hastalarında yapılan bir survey çalışmasında PET/BT volümetrik parametreleri (MTV, TLG ve TLG/karaciğer SUV) hayatta kalma ile önemli ölçüde ilişkili olarak saptanmıştır ${ }^{14}$.

Çalışmamızın retrospektif olması, örneklem büyüklüğünün küçük olması ve üç grupta 4 farklı parametreyle karşılaștırma yapılması çalışmamızın kısıtlılıklarındandır.

\section{SONUÇ}

MPM ve MPH'yi benign plevral patolojilerden ayırt etmede plevral kalınlığın SUVmax değerinin kullanılabileceği sonucuna varıldı. Mediastinal lenf nodu SUVmax değerinin MPM ile benign lezyonları ayırt edemediği ancak MPH'tan daha düşük SUVmax değerlerine sahip olduğu bulundu. Plevral kalınlaşma nedeniyle 18F-FDG PET/BT görüntüleme yapılanlarda MPM'nın tanıdaki rolünü araştırmak amacıyla dizayn edilen bu retrospektif çalıșmamızda plevral kalınlığın SUVmax cut-off değeri 6,75 
alındığında MPM'yi tespit etmede yüksek sensitivite ve spesifiteye sahiptir.

Etik Kurul Kararı: Bu çalışma yürürlükteki mevcut yasalar ve iyi klinik uygulamalar kılavuzu eşliğinde Dicle Üniversitesi Tıp Fakültesi etik komiteden onay alınarak gerçekleştirildi (Onay no:2020/99).

Çıkar Çatışması Beyanı: Yazarlar çıkar çatışması olmadığını bildirmişlerdir.

Finansal Destek: Bu çalışma her hangi bir fon tarafından desteklenmemiştir.

Declaration of Conflicting Interests: The authors declare that they have no conflict of interest.

Financial Disclosure: No financial support was received.

\section{KAYNAKLAR}

1. Bridda A, Padoan I, Mencarelli R, Frego M. Peritoneal mesothelioma: a review. Med Gen Med. 2007; 9: 32.

2. Robinson BW, Lake RA. Advances in malignant mesothelioma. N Engl J Med. 2005; 353: 1591-603.

3. Travis WD, Brambilla E, Müller-Hermelink HK, Harris CC. Pathology and Genetics: Tumors of the Lung, Pleura, Thymus, and Heart, IARC. 2004; 125-44.

4. Beckett P, Edwards J, Fennell D, et al. Demographics, management and survival of patients with malignant pleural mesothelioma in the National Lung Cancer Audit in England and Wales. Lung Cancer. 2015; 88: 344-8.

5. Sarısoy HT, İnan N, Demirci A. Plevra Patolojilerinde Radyolojik Görüntüleme, Plevra Hastalıkları ve Tedavisi. Journal of Clinical and Analytical Medicine. 2011; 10-5.

6. Bandi V, Lunn W, Ernst A, et al. Ultrasound vs. CT in detecting chest wall invasion by tumor: a prospective study. Chest 2008; 133: 881-6.

7. Nickell LT, Lichtenberger JP, Khorashadi L, et al. Multimodality imaging for characterization, classification, and staging of malignant pleural mesothelioma. Radiographics 2014; 34: 1692-706.
8. Gill RR, Patz S, Muradyan I, Seethamraju RT. Novel MR Imaging Applications for Pleural evaluation. Magn Reson Imaging Clin N Am. 2015; 179-95.

9. Elliott HS, Metser U, de Perrot M, et al. 18F-FDG $\mathrm{PET} / \mathrm{CT}$ in the management of patients with malignant pleural mesothelioma being considered for multimodality therapy: experience of a tertiary referral center. Br J Radiol. 2018; 91.

10. Metintas S, Ak G, Metintas M. Trends in malignant pleural mesothelioma in Eskisehir province of Turkey from January 1990 to December 2016. European Respiratory Journal. 2017; 50: PA1591.

11. Ocak B, Şahin AB, Dakiki B, et al. The benefit of surgery on survival for patients with stage 1 and 2 malignant pleural mesothelioma. Dicle Tıp Dergisi/Dicle Med J. 2020; 47: 770-8.

12. Yildirim H, Metintas M, Entok E, et al. Clinical value of fluorodeoxyglucose positron emission tomography/computed tomography in differentiation of malignant mesothelioma from asbestos- related benign pleural disease: an observational pilot study. J Thorac Oncol. 2009; 4: 1480-4.

13. Elboğa U, Yılmaz $M$, Uyar $M$, et al. Plevral patolojilerin ayırıcı tanısında 18F-FDG PET-BT'nin rolü: Rev Esp Med Nucl Imagen Mol. 2012; 187-91.

14. Akdeniz N, Küçüköner M, Kaplan MA, et al. The Effect of Metabolic PET Parameters on Survival Outcome in Malignant Pleural Mesothelioma. Dicle Tıp Dergisi/Dicle Med J. 2020; 47: 16-23.

15. Yu C, Xia X, Qin C, et al. Is SUVmax Helpful in the Differential Diagnosis of Enlarged Mediastinal Lymph Nodes?; Contrast Media \& Molecular Imaging. 2018; 9.

16. Kumar A, Dutta R, Kannan U, et al. Evaluation of mediastinal lymph nodes using 18F-18F-FDG PET-CT scan and its histopathologic correlation: Annals of Thoracic Medicine. 2011; 6: 11-6.

17. Lawek Berzenji, Paul E. Van Schil, Laurens Carp. The eighth TNM classification for malignant pleural mesothelioma. Transl Lung Cancer Res. 2018; 7: 5439.

18. Metintas M, Ucgun I, Elbek O, et al. Computed tomography features in malignant pleural mesothelioma and other commonly seen pleural diseases. Eur J Radiol. 2002; 41: 1-9. 